\title{
Steps for the Behavioural Based Safety: A Case Study Approach
}

\author{
Faridah Ismail and Ahmad Ezanee Hashim, Member, IACSIT
}

\begin{abstract}
A more closely monitoring on employees' behaviours proof to resolve safety problems. This paper presents the Behavioural Based Safety (BBS) approach, for workplace safety improvement. This approach focuses on changing unsafe into safe behaviour. The objective of this research is to determine the implementation steps involved for BBS approach towards safety improvement. Case Study approach into three Oil and Gas practicing BBS had been chosen. Semi-structured interview, questionnaires survey and on field observation were conducted to retrieve information. The findings revealed that the implementation steps are not limited to the four basic steps as found in literature. Unsafe work processes, unsafe condition and unsafe work procedure were identified as the additional elements noted during the observations steps.
\end{abstract}

Index Terms-Employees' behaviour, implementation steps, oil and gas, safety improvement.

\section{INTRODUCTION}

Safety problems are basically related to unsafe or careless employees, many safety problems can be resolved, if behaviours are closely monitored [1]. Despite organisations has policies and well-managed safety management, significant number of accident occurs. Workers' attitude is the common possible causes. Studies done by [2] found that the causes of accidents at the workplace were due to the workers' negligence, failure of workers to obey work procedures, and poor workers attitude about safety.

A desk study on BBS approach which is fully implemented in the Oil and Gas Industry, Malaysia proved to have shown positive results. Hence, the objective of this research is to determine the implementation steps involved with the hope that the findings will be able to be adopted in other sectors for workplace safety improvement.

\section{LITERATURE REVIEW}

\section{A. The BBS Approach and Safety Improvement}

Ref [3] revealed that the behaviour based process was developed in 1998 and was introduced as a part of a broader accident prevention programme, one that was initially focused on 'conventional' safety. Ref [4] revealed that behavioural safety does improve safety behaviour and reduce injuries based on the studies reviewed. According to [5] the

Manuscript received May 17, 2012; revised June 18, 2012.

The authors are with the Universiti Teknologi MARA, 40450 Shah Alam, Selangor, Malaysia (e-mail: farid346@salam.uitm.edu.my; ezanee54@yahoo.com). success of the behaviour based safety approach is prominent.

The concept of BBS approached refers to a systematic application of psychological research on human behaviour aimed at changing unsafe to safe behaviour, agreed among researchers [6], [7], [8], [9], and [10]. Hence, BBS is an analytical or data-driven approached, where critical behaviour get identified and targeted for change. Further, [11] highlighted that behaviour based safety interventions are people focused and are often based upon one to one or group observations of employees performing routine works tasks, feedback on safety related behaviour, coaching and mentoring.

In application BBS is a "bottom-up" approach where the primary attention is directed at specific safety related behaviours that are typically performed by frontline employees [1]. Changes in the frontline safety behaviours will improved safety performance and over time diffused into the organisation to become culture. The mode of safety intervention is effective significantly improving employee safety performance [11] and [12]. The implementation of BBS in 1991 shows a reduction of injuries rate at 54\% at the year-end 1995, indicating the possibility of BBS is applicable to other sectors [13].

\section{B. The Implementation Steps}

According to [7], the basic behaviour-based process consists of identifying observable safe behaviours upstream in the process. Then, identification of the antecedents (activators) that encourage these safe behaviours is needed and encouraging workers to practice it. Hence, the recognition of antecedents that discourage safe behaviours required to be removed. The Total Quality Management (TQM) approach to safety offers more long-lasting results, but behaviour modification gives quicker impact, especially with specific, observable problems [14].

Ref [15] acknowledged that behaviour-based approaches to safety focus on systematically studying the effects of various interventions on target behaviours, first by defining the target behaviour in a direct observable and recordable way, and second by observing and recording it in its natural setting. When a stable baseline measure of the frequency, rate, or duration of behaviour is obtained, an intervention is implemented to change the behaviour in beneficial directions. Further, studies done by [1] and [16] suggested that the typical implementation of behaviour-based safety program usually involves four well-defined steps [17].

According to [7], the basic behaviour-based process consists of identifying observable safe behaviours upstream in the process. Then, identification of the antecedents (activators) that encourage these safe behaviours is required for workers to practice it. Recognition of antecedents that 
discourage safe behaviours is required and removes them. Behaviourist theory said those consequences (reinforcement) that are positive, immediate and certain (rewards) will keep employees working safely. Negative consequences which are immediate and certain (rewards) discourage unsafe behaviours.

Ref [18] agreed the BBS steps that have been studied by [19] start by defining one or more critical behaviour target. These behaviours are observed and recorded in particular work settings. When a relatively stable baseline measure of the frequency, duration, or rate of behaviour is obtained, an intervention is implemented to change behaviour in beneficial directions. However this intervention might involve removing environmental barriers, modifying a workstation, or adding antecedents or consequences to the situation to alter response probability. The frequency, duration, or rate of the target behaviour is recorded during and after the intervention and compared to baseline measures of behaviour to determine the impact of intervention.

\section{RESEARCH METHODOLOGY}

Three Oil and Gas companies practicing BBS had been chosen as the case study. Semi-structured interview, questionnaires survey and on field observation were conducted to retrieve information from all the three case studies. Interviews were conducted with relevant personnel and those who are involved in the behavioural based safety program which includes the Safety and Health Manager, BBS Facilitator, Safety and Health Officer / Supervisor, Project Manager and Project Engineer. Three interviewees were selected among these key personnel at each of the case study. The interview solicits the organisations' background, establishment and the implementation steps involved in the BBS practice.

In addition, forty (40) questionnaires distributed for each case study to seek the current implementation of BBS from the safety officers, safety supervisors, project managers, project engineers, supervisors and others management staffs and technical staffs. The survey questions consist of 3 parts; Part A: solicit data on personal information and organisation background, Part B, focus on its implementation and Part C; assess on the management support towards safety improvement. Management practice towards safety improvement has been divided into two, Safety and Health Policy statements and Behaviour Based Safety (BBS) approach.

Observation was carried out to validate the information and data collected during interviews and questionnaires survey. The technique of the BBS observation carried out at workplace was also noted.

\section{RESUlTS AND DisCUSSION}

The interview held and the questionnaire survey with a respond rate of $55 \%(22), 35.5 \%$ (15), $47.5 \%$ (C) from company $\mathrm{A}, \mathrm{B}$, and $\mathrm{C}$ respectively revealed the following results;

Integrated are the major facets of Company $\mathrm{A}$, where oil is one of the major products, with a total refining capacity of more than 448,000 barrels per day. The BBS programme headed by the Behavioural Safety Department has been developed since May 2006 with the aim of creating a more positive Health, Safety and Environment culture.

The implementation is divided into 5 phases, planning, launching, and implementation, monitor and review and program adjustment. At the planning phase, flowchart is drawn showing the plant area to be covered, the target date, activities, cost budget and parties involved. This phase involves the whole processes and programs framework until the programme is fully implemented. It includes the preparation of observation form, promoting strategies, training module, workshop and presentation show. Training provided periodically to all parties during the implementation phase. The implementation include on site observation.

Further, the observation comprised of 3 steps; the initial steps involved notifying the Behavioural Safety facilitator if any assistance is required. The observer will determine the workplace to be observed and decide on the sample size. Related forms secured and observation conducted where information noted. Lastly the observer will submit completed observation form to the department.

The department listed 5 simple steps on how to conduct observation; notify, observe, act or discuss, agree and thank. Observer has to introduce themselves to the workers and explain the purpose of observation. Then, the observer shall seek the permission and ask workers to continue with their current works. Both safe behaviour and unsafe behaviour practice by the workers are observed and noted. Unsafe behaviour practiced is intervened where discussion held encouraging for a safer working method. The observer has to ensure that the workers agree and change unsafe behaviour practice to safe behaviour practice. At the last steps, the observer has to appreciate and thank to the worker for their co-operation. Principles of behavioural safety observation is to recognise safe behaviours, identify unsafe behaviours, conduct observation with openly and honestly and do not record workers' name and avoid blaming.

Company B was incorporated in Malaysian on September 1960. Developed within 333 acres of area, the principal activities are refining and manufacturing of petroleum product. Their activities include the processing of crude oil and produce a wide range of petroleum products where over 85 percents of which are consumed in Malaysia. Company B refinery has developed Health, Safety, Security and Environment Management System (HSSE MS) as one of company strategy to achieve company mission and vision and objectives.

This company innovate the BBS approach and used the concepts of Positive Intervention Walkabout (PIW) instead. Though embedded within the four main steps [17], many elements and activities are involved. The PIW consist of coaching, cross section visit, intervene and action, cover all area, emphasizing personal and process safety, self follow-up, safety is everybody responsibilities, web link and appreciating the employee. Each group consist a minimum of two staffs or maximum 4 staffs, and at least one experience staff and junior staff. Unlike the common BBS approach, PIW not only observe unsafe behaviour, but also recorded 
unsafe condition, unsafe work process and unsafe work method. Observation will be done at the dedicated area based on the yearly observation schedule set.

Company $\mathrm{B}$ divided the refinery area into 14 observation areas and was marked with alphabet from ' $A$ ' to ' $N$ '. Nine departments in the refinery will form up their own observation groups with the composition of personnel set. Each group will observe at least 3 areas every year. Observation will be conducted through 4 steps; identify the area, conduct observation, intervene and close action and write and submit report.

Company C, developed on 604 acres of land area, and has been in operation since 1963. It processes crude oil into petroleum product for daily use by consumers. The product include cooking gas (LPG-Liquefied Petroleum Gas), motor gasoline, jet fuel, kerosene, diesel, fuel oil and low sulfur residue. From a moderate operation of 24,000 barrels per day, the refinery has expanded with a current production of more than 80,000 barrels of crude oil per day.

The BBS implemented since 1999 has been improved to include a combination of people safety (BBS) and process safety and termed as Loss Prevention System (LPS). The objective of LPS is to provide all employees with a safe, healthy and loss-free workplace. The concept of LPS is to identify unsafe behaviour, unsafe condition and unsafe work process. LPS used five tools; Job Safety Analysis (JSA), Safe Performance Self Assessment (SPSA), Loss Prevention Observation (LPO), Near Miss/Incident Investigation and Stewardship.

Job Safety Analysis (JSA) is a tool prepared by workers and their supervisor to study and record each steps of a job, identifying potential hazards and determine the best way to do the job safely and properly. Five basic steps of JSA are; identifying job to be analysed, determine key job steps, identify potential hazards in each job step, develop measures to eliminate or control the hazard and follow the JSA in the course of doing the job and improve it where necessary. Safe Performance Self Assessment (SPSA) is a tool for everybody before start working. Three simple steps of SPSA are assessing the risk, analyse how to reduce the risk and act to endure safe operations. Loss Prevention Observation (LPO) is a major tool for Loss Prevention System (LPS), system used to minimise incidents. The LPO is a systematic standardized tool for observing work process and determining whether job is being done in accordance to the specific standards. Hence, LPO aimed at identifying unsafe behaviour, unsafe condition and unsafe work process and ensuring work is done correctly and safely. The LPO process is divided into 8 steps; Identification of target areas, selection of observers and scheduling observations, preparation for observation, conduct observation, feedback discussion session, quality review and approval by Area/ Department/Operation Manager, communication and implementation of solution and recommendation and verification and validation of solutions.

Generally all respondents have attended behavioural based safety training. In company A, 54\% attended between 2 to 7 days per year, $41 \%$ more than 7 days per year and the remaining $5 \%$ have attended only one day per year. Similarly in company B, $67 \%$ attended between 2 to 7 days and the remaining 33\% attended more than 7 days. A high percentage is recorded for company $\mathrm{C}$, attended more than 7 days per year at 58\% and remaining $42 \%$ attended training between 2 to 7 days per year.

All respondents at three case study companies unanimously agreed that advantages of Behaviour Based Safety (BBS) approach has improve safety performance, reducing the number of accidents, train workers to practice safe behaviour, reducing loss time injury, improving safety culture and others such as change worker's behaviour, unsafe behaviour can be identified and eliminated, good worker's attitude, improving safe work environment, practice you see and you act, safety is everybody responsibilities, no body get hurt and improving worker's health quality. The findings revealed that there is an innovation from the four basic steps; identify, observation, intervene, review and monitoring. Unsafe work processes, unsafe condition and unsafe work procedure were identified as the additional elements noted during the observations steps. Hence, the term BBS has been innovated to PIW and LPO to accommodate for these additional elements observed. The summary of the differences is illustrated in Table 1.0 as in the Appendix.

\section{CONCLUSION}

This paper set out the implementation steps involved under the BBS approach towards safety improvement. The approach focuses on identifying unsafe workers behaviour and intervene it to safe behaviour practice. However the analysis of the three cases studies shows that the concept includes the process, procedures and the unsafe condition.

The basic implementation steps of BBS approach under the case study are identify, observe, intervene and feedback and report. However, innovation into the new term as Positive Intervention Walkabout (PIW) were revealed through Company B. PIW is a combination of behaviour based safety and process safety where they believe that this combination forms a comprehensive approach to improve safety performance. This include coaching, cross section visit, intervene and action, cover all area, emphasizing personal and process safety, self follow-up, safety is everybody responsibilities, web link and appreciating the employee were identified. Further Company $\mathrm{C}$ innovate BBS into LPO process accommodated within 8 steps; Identification of target areas, selection of observers and scheduling observations, preparation for observation, conduct observation, feedback discussion session, quality review and approval by Area/Department/Operation Manager, communication and implementation of solution and recommendation and verification and validation of solutions.

Results from the questionnaires survey, unanimously agreed that BBS approach is effective approach and can be introduced to others industries including construction. BBS has been acknowledged to improve safety performance, reduce the number of accident, workers practice safe behaviour, reduce lost time injury, improving safety culture and unsafe act or behaviour can be identified and eliminated. This study has identified the implementation steps and it is hope that the findings will be able to be adopted in other sectors for workplace safety improvement. 


\section{ACKNOWLEDGMENT}

The authors wish to thank the reviewers for their invaluable comments on this paper. Special thanks to Mr.Mohd Adnan Mahmood, a Safety Officer who assisted in the research study.

\section{APPENDIX}

TABLE I: SUMMARY ON THE FINDINGS OF THE CASE STUDIES

\begin{tabular}{|c|c|c|c|}
\hline & Company A & Company B & Company C \\
\hline$\frac{0}{2}$ & $\begin{array}{l}\text { 1. Implemented } \\
\text { Behaviour } \\
\text { Based Safety } \\
\text { since } 2006 \\
\text { 2. They name it as } \\
\text { Behavioural } \\
\text { Safety. }\end{array}$ & $\begin{array}{l}\text { 1. Implemented } \\
\text { Behavior Based } \\
\text { Safety approach } \\
\text { since } 2003 \text {. } \\
\text { 2. Revised and } \\
\text { improving the } \\
\text { BBS approach } \\
\text { with combination } \\
\text { BBS and Process } \\
\text { Safety and name } \\
\text { it as Positive } \\
\text { Intervention } \\
\text { Walkabout (PIW) }\end{array}$ & $\begin{array}{l}\text { 1. Implemented } \\
\text { Behaviour Based } \\
\text { Safety since 1999. } \\
\text { 2. Revise and } \\
\text { improving the BBS } \\
\text { approach at the early } \\
\text { stage of } \\
\text { implementation with } \\
\text { combination of BBS } \\
\text { and Process Safety } \\
\text { and name it as Loss } \\
\text { Prevention System } \\
\text { (LPS) }\end{array}$ \\
\hline 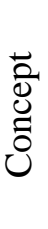 & $\begin{array}{l}\text { Observe and } \\
\text { identify unsafe } \\
\text { act and unsafe } \\
\text { condition at the } \\
\text { work place and } \\
\text { intervene it. }\end{array}$ & $\begin{array}{l}\text { Observe and } \\
\text { identify unsafe act, } \\
\text { unsafe condition, } \\
\text { unsafe work process } \\
\text { and procedure and } \\
\text { intervene it with self } \\
\text { follow-up }\end{array}$ & $\begin{array}{l}\text { Observe and identify } \\
\text { unsafe act, unsafe } \\
\text { condition, unsafe work } \\
\text { process and procedure } \\
\text { and intervene it. }\end{array}$ \\
\hline 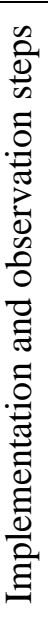 & $\begin{array}{l}\text { Four steps of } \\
\text { Behavioural } \\
\text { Safety } \\
\text { Observation } \\
\text { 1. Plan BS } \\
\text { Observation } \\
\text { 2. Conduct } \\
\text { Observation } \\
\text { 3. Completed } \\
\text { observation } \\
\text { form or } \\
\text { feedback } \\
\text { 4. Review and } \\
\text { Monitor }\end{array}$ & $\begin{array}{l}\text { Four steps of PIW } \\
\text { observation. } \\
\text { 1. Identify } \\
\text { 2. Conduct } \\
\text { Observation } \\
\text { 3. Intervene } \\
\text { 4. Report }\end{array}$ & $\begin{array}{l}\text { Loss Prevention } \\
\text { Observation was } \\
\text { conducted through } 8 \\
\text { steps. } \\
\text { 1. Identification of } \\
\text { target area } \\
\text { 2. Selection of } \\
\text { Observer \& Schedule } \\
\text { Observation } \\
\text { 3. Preparation of } \\
\text { observation } \\
\text { 4. Conduct Observation } \\
\text { 5. Feedback discussion } \\
\text { 6. Review and approval } \\
\text { 7. Communication and } \\
\text { recommendation } \\
\text { 8. Verification and } \\
\text { validation of } \\
\text { solutions }\end{array}$ \\
\hline
\end{tabular}

\section{REFERENCES}

[1] D. M. Dejoy, "Behaviour Change Versus Culture Change: Divergent Approaches to Managing Workplace Safety," Safety Science, 2005, pp.105-129.

[2] A. H., Abdul Rahim, A. M., Muhd Zaimi, and S.Bachan, "Causes Of Accidents at Construction Sites," Malaysian Journal of Civil Egineering, 2008, pp. 242-259.

[3] S. Cox, B. Jones, and H. Rycraft, "Behavioural Approaches to Safety Management Within UK Reactor Plants," Safety Science, 2004, pp. 825-839

[4] M. D. Cooper (2009). Behavioral Safety: A review of process design factors'. Professional Safety, 54 (2), pp 36-45

[5] D.Cruthirds and S.Pittman, "Behaviour Based Safety Process, An Effective Compliment To OSHA Complience," 1996, pp.263-273.

[6] H. Lingard, S.Rowlinson, "Behaviour-Based Safety Management in Hong Kong's Construction Industry," Journal of Safety Research, 1997, pp. 243-256.

[7] T. A Smith, "What wrong with behaviour-based safety," Professional Safety, 1999, vol. 44, no.9, p37-40.

[8] R. B. Elsberry, "The Key to a Safe Workplace,” Electrical Apparatus; June 2003, pp.49.
[9] D. M.Dejoy, "Behaviour Change Versus Culture Change: Divergent Approaches to Managing Workplace Safety," Safety Science, 2005, pp. 105-129.

[10] R. M. Choudhry, D. Fang, and S. Mohamed, "Developing A Model of Construction Safety Culture," Journal of Management in Engineering, 2007, pp. 207-212.

[11] S. Cox, B. Jones, and H. Rycraft, "Behavioural Approaches to Safety Management Within UK Reactor Plants," Safety Science, 2004,pp. 825-839

[12] J. Komaki, D. Kenneth, Barwick, and R. S Lawrence,"A Behavioral Approach to Occupational Safety: Pinpointing and Reinforcing Safe Performance in a Food Manufacturing Plant," Journal of Applied Psychology, 1978, pp. 434-445.

[13] B.Jerry, T. C. Caldwell and Stan Hodson, (1997), Behavior-Based Safety in Action, Occupational Health \& Safety, pp. 80.

[14] A. Suraji, A. R. Duff, and S. J. Peckitt. "Development of casual model of construction accident causation." Journal of Construction Engineering and Management, 2001, 127(4), 337-344.

[15] E. S. Geller,"Behaviour Based Safety in Industry: Realizing the Large-scale Potential of Psychology to Promote Human Wellfare", Applied \& Preventive Psychology, 2001, pp. 87-105.

[16] T. R. Krause, K. J., and K. C. M. Sloat, "Long-term Evaluation of a Behavior-based Method for Improving Safety Performance: a Meta-analysis of 73 Interrupted Time-series Replications," Safety Science, 1998, pp. 1-18.

[17] I. Faridah., H.Ahmad Ezanee, S.Rahmatul Hidayah and M. Mohd Adnan, "Behaviour Based Safety Approach: A Mechanism for Workplace Safety Improvement," in Proc. International Conference of Construction Project Management (ICCPM), Chengdu, China 16-18 November 2010.

[18] J. P. DePasquale, and E. S. Geller, "Critical Success Factors for Behaviour-Based Safety: A Study of Twenty Industry-wide Applications", National Safety Council and Elsevier Science Ltd, USA,1999, pg. 237-249.

[19] E. S. Geller, T. E. Boyce, J. H. Williams, C. B. Pettinger, J. P. DePasquale, and S. Clarke, "Researching Behavior-Based Safety: A Multi-Method Assessment and Evaluation", 37th Annual Professional Development Conference and Exposition, American Society of Safety Engineers, 1998.

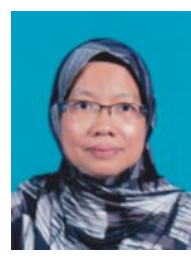

Faridah Ismail was born in the state of Johor, Malaysia, in 1958. She is currently served as the head of centre in quantity surveying studies, Faculty of Architecture Planning \& Surveying, UiTM Shah Alam, Selangor, Malaysia. She had a background cumulative working experience of more than 20 years at two prominent and established organisationsx; Public Works Department (PWD) and the Construction Industry Development Board (CIDB) respectively. Possessing a Bachelor of Science in Quantity Surveying, M.Sc in Construction Management spurs the spirit to be honored a $\mathrm{PhD}$ in Built Environment (Safety Culture). Currently teaching and supervising both the undergraduate and post-graduate students in the subjects of Construction Management, Strategic Management, and Construction Economics shows her research interest is not limited to safety culture and behavioural studies.

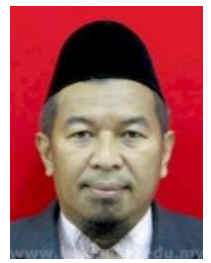

H. Ahmad Ezanee was born on 1954 at Kelantan, Malaysia. Currently, he served as the Senior Lecturer, Centre of Building Surveying Studies, Faculty of Architecture Planning \& Surveying, UiTM Shah Alam, Selangor, Malaysia. He also possessing as pioneer's creation of the Professional Scheme in the Public Services Department Grade J45 and Technical Assistant Building Survey J29, J36 and J38 at the Department of Public Services at national level. Thus, he connected to recognition networking professional at the International Level on Royal Institute of Chartered Surveyors UK. In that order, he had 22 years working experiences at establishes organizations, Institute Surveyor Malaysia (ISM) and the Construction Industry Development Board (CIDB). He is actively involved with Building Surveying Professional Certification Department at the Institute of Surveyors Malaysia since 1991. Possessing a Bachelor of Science in Building Surveying, M.Sc in Facilities Management and he is honored a $\mathrm{PhD}$ in Built Environment. At present he is teaching both the undergraduate and post-graduate students in the subjects of Facilities Planning and Management of Building Fabric, Sustainable Facilities Management and Integrated Simulation Facilities Management Project. 